\title{
DOS LECTURAS COMPLEMENTARIAS DE LA PENALIDAD CONTEMPORÁNEA. IMPLICACIONES POLÍTICAS EN TORNO A LA EMERGENCIA Y CONSOLIDACIÓN DE LA TEORÍA DEL DELITO*
}

Two Additional Readings of Contemporary Penalty. Political Implications Surrounding the Emergence and Consolidation of the Crime Theory*

\section{Miguel Antonio Morón Campos**}

Fecha de Recepción: Noviembre 4 de 2013

Fecha de Aceptación: Noviembre 11 de 2013

SUMARIO: 1. Introducción; 2. Matices culturales del poder penal: emergencia y consolidación; 3. EI derecho penal: un saber dicotómico; 4. Consideraciones finales; 5. Referencias bibliográficas.

\footnotetext{
* Resultado Final de Investigación derivado del proyecto "Bifurcaciones Discursivas del Populismo Penal en América Latina", el cual fue financiado por el Tecnológico Comfenalco en el marco de la convocatoria interna de proyectos de menor cuantía 2013.

** Abogado egresado de la Universidad de Cartagena. Miembro del grupo de investigaciones Sociales y Jurídicas de la Fundación Universitaria Tecnológico Comfenalco-Cartagena. Director del semillero Castigo y Sociedad. Estudiante de la Maestría Conflicto Social y Construcción de paz de la Universidad de Cartagena (III Cohorte). mmoron@tecnocomfenalco.edu.co
} 


\section{COMO SE CITA ESTE ARTÍCULO (APA 6)}

Morón Campos, M. A. (2014) Dos lecturas complementarias de la penalidad contemporánea. Implicaciones políticas en torno a la emergencia y consolidación de la teoría del delito. (Y. Carrillo De la rosa, Ed.) Revista Jurídica Mario Alario D'Filippo, VI (11), pág. 50-59

\section{RESUMEN}

El objetivo de este trabajo es analizar las implicaciones políticas que supone la consolidación de la teoría del delito contemporánea desde una perspectiva que comprende el estudio de la penalidad como efecto de las tecnologías de poder. A partir de las herramientas genealógicas que aporta la obra de Zaffaroni en torno a la emergencia del derecho penal, se expondrán algunos matices culturales que supone la cotidianidad del poder penal, para así, desde el análisis criminológico de la obra de Christie sobre las imágenes del hombre en el derecho penal, explicar las tensiones y efectos que suscita en la teoría penal contemporánea. En ese sentido, esta investigación documental, la cual supone un enfoque cualitativo, implica brindar herramientas para la comprensión y explicación de los efectos sociales de la sistemática del delito; es decir, un análisis que se articula dentro de los marcos de la sociología de la penalidad, revisando los usos constitutivos del saber jurídico-penal.

\section{PALABRAS CLAVE}

Penalidad, poder punitivo, teoría del delito, discurso, criminología.

\section{ABSTRACT}

The aim of this paper is to analyze the political implications posed by the consolidation of the contemporary crime theory from a perspective that includes the study of the penalty as a result of power technologies. From genealogical tools provided by the work of Zaffaroni around the emergence of criminal law, some cultural overtones involved in the everyday life of penal power, so that from the criminological analysis of the work of Christie on man images in criminal law, explain the tensions and effects aroused in contemporary penal theory. In that sense, this documentary research, which represents a qualitative approach, involves providing tools for understanding and explanation of the social effects of systematic crime; that is, an analysis that is articulated within the framework of the penalty sociology, reviewing the constituent uses of the criminal legal knowledge.

\section{KEYWORDS}

Penalty, the punitive power, theory of crime, speech, criminology. 


\section{INTRODUCCIÓN}

El castigo. Causar dolor, corregir duramente, la práctica de imponer algo desagradable a un individuo que ha hecho algo inconveniente. Dependiendo del escenario, el castigo es una marca sobre el cuerpo, exclusión del sujeto o limitación de la libertad para reformar el espíritu. El castigo es un mal desagradable. Es curioso ver en los tratados de derecho penal que la facultad de castigar, el iuspuniendi o derecho penal subjetivo en el argot penalista usa la palabra "pena" igualando en su contenido a "castigo", como si fueran sinónimos. Sin embargo, a la hora de abordar la concepción de pena, esta es comprendida como la supresión de un bien jurídico-la libertad-con que se amenaza y se aplica a quien realiza un precepto legal con dichas consecuencias jurídicas, "es asegurarse que el culpable no reincida en el delito y lograr que los demás se abstengan de cometerlo" (Beccaria, 2010, pág. 39), "es el restablecimiento del orden externo de la sociedad" (Carrara, 2004, pág. 29), "es la que asegura la defensa social cumpliendo una función preventiva" (Ferri, 2004, pág. 45). Es una práctica que materializa la coerción (legítima) del Estado, pretendiendo mantener una estabilidad entre sus asociados. La pena es un bien social.

Las motivaciones contrarias que guardan estos dos conceptos tienen un elemento común, tanto "pena" como "castigo" obedecen a un acto de violencia, "Quien la ejerce" es lo que determina su motivación cobijándolo con un rótulo de legitimidad, pervirtiendo todo acto de violencia como bien social. Max Weber definió el Estado moderno como la institución que poseía el monopolio de la coerción legítima, licita, única y omnipotente. La única agencia autorizada a desplegar el accionar coercitivo, a forzar que el estado de cosas existente sea diferente de lo que ha sido y seguirá siendo si se lo dejan librado al mismo (Bauman, 2004, pág. 10). Esta legitimidad para ejercer violencia implica que aquel que la ejerce le suprime el derecho a resistirse, cuestionar sus motivos, vengarse o exigir compensación a aquel que la padece (Bauman, 2004, pág. 10). El Estado en su facultad de castigar, se convierte en juez y parte, siendo su mayor preocupación la invención de otras agencias que emulen el ejercicio del poder (Foucault, 1996, pág. 111), razón por la cual se atribuye el monopolio de los medios para ejercer violencia.

Un objetivo que se explicaba en tanto puesta en práctica del modelo de realidad que se prefería por sobre todos los otros: más racional, más humano, o supuestamente más seguro, y por cualquiera de estas razones, superior a las alternativas en pugna o posibles de pasar a integrar el debate.(Bauman, 2004, pág. 12)

El derecho penal es un instrumento de control social con un alto contenido de violencia (MuñozConde, 1985, pág. 18); no solo violento por aquello que pretende abarcar: homicidios, hurtos, constreñimientos, etc. Violento en tanto el acto arbitrario de decidir qué es lo ilegítimo, de atribuirse la capacidad de enunciar lo permitido y los procedimientos en que se pueda usar esta permisión. El discurso del castigo legítimo, iuspoenale o derecho penal objetivo, tendrá como propósito seleccionar las situaciones en que debe activarse el poder punitivo estatal, selecciona a las ovejas descarriadas, gamberros, anormales y enemigos de la tranquilidad social, brindándole tratamiento, educación o reformación motivada al camino de la normalidad.

La teoría del delito, "como el universo dentro del cual debe construirse un sistema de comprensión 
que explique cuáles son las hipótesis y condiciones que permiten formular el requerimiento punitivo" (Zaffaroni, 2002, pág. 4), lejos de rotular un tipo de subjetividad, la idea de "el delincuente" constituye en sí mismo un proceso de construcción que da nacimiento a nuevos sujetos de conocimiento fuera de la esfera penal. (Foucault, 1996)

En ese sentido, este trabajo pretende mostrar en primera medida las implicaciones culturales y políticas que soporta la emergencia de la teoría del delito, a partir de los usos constitutivos de esta y los efectos históricos que esta supone. Seguidamente, desde la sociología del castigo se abordará el problema de cómo la teoría del delito constituye nuevos tipos de subjetividades que están fuera de los límites teóricos del derecho penal. Por último se expondrán unas consideraciones finales de como la teoría penal, además de ser un instrumento que "reduce y contiene el poder punitivo para impulsar el progreso del estado constitucional de derecho (Zaffaroni, 2002, pág. 5), es un discurso de poder que legitima decisiones y domina el porvenir de determinado grupo.

\section{MATICES CULTURALES DEL PODER PENAL: EMERGENCIA Y CONSOLIDACIÓN}

Todo el discurso del poder punitivo se construye a partir de una emergencia (Zaffaroni, 2006). Lo que actualmente conocemos como derecho penal obedece a toda una serie de reformas legislativas atribuidas a una serie de personajes que históricamente se les ha llamado iluministas o contractualistas (Bustos \& Bergalli, 1983, pág. 27). Uno de los puntos por los cuales emerge es, además de la filosofía liberal, el pensamiento racionalista impuesto sobre las prácticas punitivas que guardaba el Acien Regime.

El derecho penal pre-moderno fue un discurso construido a partir de un criterio teocrático/biologista. Legitimación de la crueldad, degradación de la imagen humana por parte del inquisidor, discriminación biológica antifeminista del poder bendito. El Malleus Malleficarum o el Martillo de las Brujas (Kraemer \& Sprenger, 1986) es quizás el primer modelo integrado de derecho penal que teoriza el poder punitivo ${ }^{1}$. La fiesta punitiva con que se activaba la barbarie criminalizante era el proceso inquisitorial. Todas las conductas que atentaran o fueran en contra de la inquisición se transformara automáticamente en coerción directa, "importa considerar que toda infracción es parte de una agresión actual y por ende, todo el poder punitivo se ejerce en situación de legítima defensa" (Zaffaroni, 2006, pág. 113) esta situación ubica al ofensor en un sitio de poder que habilita ejercer un acto de violencia contra un acto de violencia ilegítimo sin darle importancia alguna los medios o límites con que esta violencia se ejerce. Con esta lógica se legitima y se le da vía libre a la tortura como medio para obtener la verdad. "el procedimiento inquisitorial obligaba mediante tortura a denunciar a todos los sospechosos, de modo reproductivo al infinito. Sus ventajas para el poder rápidamente lo extendieron a los tribunales laicos, donde se aplicó con mayor extensión a un los eclesiásticos". (Zaffaroni, 2006, pág. 115)

El ritual del castigo pre-moderno daba a los inquisidores la tripartita labor de defensor, acusador y

${ }^{1}$ El Malleus Malleficarum se divide en tres partes: 1) Teoría Criminológica; 2) Teoría Penal; 3) Teoría Penológica, Procesal Penal y Criminalística. (Zaffaroni, 2002) 
juez. Los controles a la defensa eran excesivamente estrictos y era forzosamente amenazado si excedía los límites de su función. "la resistencia al tormento era una prueba de ayuda diabólica, y la confesión bajo tormento era una prueba de culpabilidad de modo que siempre se hallaba culpable al procesado" (Zaffaroni, 2006, pág. 115). La mínima posibilidad de indicio activaba la tortura y el hecho de confesión bajo tortura a otra bruja era indicio suficiente para reproducir nuevamente este modelo de verdad. Reproducción al infinito de rotulación anti-femenina.

La ritualización en cuanto soporte teórico es tan radical que no puede separar la idea de infracción con la de autor. El Martillo de las Brujas constituye un manual para preparar y formar a quienes deben reconocer el mal².

Esta descripción se inicia poniendo de manifiesto algo que luego pasara a ser un elemento tácito o implícito del discurso: la indemnidad de quienes ejercen el poder punitivo, para lo cual afirma que contra ellos, el maligno nada puede y por lo tanto, tampoco pueden sus agentes, que son las brujas (el poder punitivo nunca admite la corrupción de sus agencias).

Esto deja inmunes al mal a los inquisidores. (Zaffaroni, 2002, pág. 273)

El despliegue de contenidos sobre el sujeto criminalizado ocupa un espacio en el cual no deja actividad alguna por fuera: como se inician las brujas, como pactan con el maligno, su transportación, copulación y como hacen uso de los sacramentos, la obstaculización de la función procreadora, la neutralización de la potencia masculina, la conversión de los hombres en animales, como generan enfermedades, epidemias, tormentos, catástrofes, matan niños ofreciéndolos al diablo, etc. (Zaffaroni, 2002, pág. 274). El discurso del derecho penal pre-moderno se ocupa de criminalizar signos de una inferioridad, de ahí su necesidad de mostrarse como un texto abierto dejado a función de adecuación a los arbitrarios designios del intérprete. Esta teorización del autor convierte al Malleus Malleficarum como el texto que rotula toda conducta sospechosa, un texto que sataniza la diferencia.

Frente a la teorización del poder punitivo pre-moderno se construye el derecho penal liberal, un discurso legalista que exige proporción entre las penas y el delito y canoniza el delito como perjuicio social. Fue ese el momento en el que la emergente clase burguesa toma las riendas del poder político, situándose como clase dominante. Esta nueva subjetividad se muestra como dominus a partir de un discurso que proyecte la idea de buen gobierno, sobre la riqueza de las naciones, los modos de preservar el orden, la concordia, la felicidad pública, etc. (Pavarini, 2003, pág. 27). Es un discurso cargado de optimismo, rechazando las viejas prácticas y proyectando nuevas formas institucionales que mantengan el orden.(Morón, 2009)

La reforma y teorización del sistema penal moderno ocurre después de la revolución francesa y se construirá a partir del contrato. Fue ese el momento en que el derecho penal es levantado y ocultado tras las nubes del poder, lejos de las miradas espectadoras, escondiendo las formas sanguinarias con las que se reproducía anteriormente. Ahora se postrará a la diestra del príncipe,

\footnotetext{
${ }^{2}$ Más adelante, en el siglo XIX con estos presupuestos se construirá la idea de peligrosidad propia del positivismo criminológico. (Morón,
} 2009) 
quien es el único legítimo para administrar el pacto social, siendo la ascensión el acto que genera el principio de legalidad en materia penal.

Solo el príncipe podrá determinar que es lícito y que es penalmente ilícito, y su voluntad se expresara en esta ley; esta debe ser clara e inequívoca para que los particulares siempre sean conscientes de la esfera de su propia autonomía y libertad; el juez no podrá nunca transformarse en legislador, por lo tanto la interpretación de la ley debe ser circunscrita y disciplinada; la ley penal podrá decidir solo para el presente y para el futuro, nunca para el pasado, a fin de que, en el posible conocimiento de la voluntad del príncipe, se tenga certeza de las propias acciones y relaciones. (Pavarini, 2003, pág. 30)

Esta nueva teorización del castigo envía al olvido el discurso teocrático/biologista y construye un nuevo discurso básicamente a partir de las siguientes premisas: la separación entre la infracción y la falta religiosa, la ley penal no debe apelar a la ley natural o religiosa sino reprimir lo que es nocivo, porque ataca lo que es útil para la sociedad; el criminal es un enemigo social, alguien que daña a la sociedad o el que ha roto el pacto social, el criminal es un enemigo interno; la ley penal no debe prescribir una venganza sino facilitar la reparación de una perturbación causada. (Carrillo, 2009, pág. 86)

La nueva lógica legalista del castigo se fundamenta bajo los límites de una idea: La Retribución. La ley penal estará proyectada para mediar el daño que un individuo le ha causado a otro, la ley penal secuestra a la víctima de la infracción adueñándose del conflicto y prohibiendo la venganza. Esta nueva teorización puede desenvolverse en deportación, trabajo forzado, vergüenza, escándalo público o talión (Foucault, 1996, pág. 95), es una ley teorizada en torno a la infracción que responda a criterios de utilidad pública.

Con la invención de la prisión, la teoría del delito adquiere un cambio cualitativo respecto al saber legalista propio de los iluministas, "no intentan señalar aquello que es socialmente útil sino, por el contrario, tratará de ajustarse al individuo" (Foucault, 1996, pág. 96). El principio de legalidad ya no será inquebrantable y será el juez quien lo moldeará según las circunstancias e intereses del caso concreto, la utilización de subrogados penales y criterios que habiliten circunstancias atenuantes o agravantes adquirirá mayor importancia en los espacios de discusión académica expuestos en forma de hipótesis.

En ese sentido, esta nueva forma de penalidad se construirá y fundamentara como control. Se activará como ejercicio previo de aquello que es penalmente ilícito a partir de la construcción de virtualidades potenciales que afecten el orden.

Así, la gran noción de la criminología y la penalidad de finales del siglo XIX fue el escandaloso concepto, en términos de teoría penal, de peligrosidad. La noción de peligrosidad significa que el individuo debe ser considerado por la sociedad al nivel de sus virtualidades y no de sus actos; no al nivel de las infracciones efectivas a una ley sino de las virtualidades de comportamiento que ellas representan.(Foucault, 1996, pág. 97)

El derecho penal como control social ya no se limita a una teorización que sirva de herramienta a los 
jueces sino que se desplegará a una serie de poderes laterales al margen de la justicia, "tales como la policía y toda una red de instituciones de vigilancia y corrección: la policía para la vigilancia, las instituciones psicológicas, psiquiátricas, criminológicas, médicas y pedagógicas para la corrección" (Foucault, 1996, pág. 98). Esta pluralidad de poderes encargados de la penalidad carcelaria generará un modelo integral de ciencia penal. La antropología penal, la criminología, la medicina legal, la criminalística, serán los nuevos saberes que darán soporte a la teoría del delito teniendo como objeto común el delincuente. Sin embargo, este modelo integrado es lo que llevar a un segundo plano a la teoría del delito, presentándolo como una actividad estrictamente jurídica ${ }^{3}$ y por lo tanto, maquillada bajo neutralidad y objetividad de la legalidad penal.

La teoría del delito como saber que ostenta un poder, está vinculada en su invención a otra pluralidad de saberes que pretenden ejercer un control sobre los individuos por medio de la violencia legítima, en ese sentido la teoría del delito en su construcción no puede separarse del poder policial, el saber médico o el saber sociológico porque es a partir de todos estos en los que se trata de moldear las virtualidades que atenten contra el orden social, oscureciendo los conflictos a una simple relación dicotómica de un sujeto que dañando a otro debe ser dañado por un tercero.

\section{EL DERECHO PENAL: UN SABER DICOTÓMICO}

El discurso jurídico del castigo se esfuerza por esconder cualquier marca de violencia generada por los saberes laterales que aborden la tensión, es un discurso neutral, que no distingue clase social, raza, capacidad económica o cualquier agregado que dé pie a la discriminación. El principio de legalidad penal predica que la ley es igual para todos. Sin embargo, esta "humanización de las penas" no puede dejar de lado que la pena es un mal con intención de ser eso, y la rama del saber jurídico que se ocupa de este mal, está equipado con las expectativas de lo que va a pasar, "en el derecho penal alguien debe sufrir, por lo tanto existe la necesidad de distinguir entre blanco y negro, bueno y malo, inocente y culpable, amigo y enemigo. El derecho penal es la actividad del esto y el aquello, es el discurso de las dicotomías"“'. (Christie, 1989, pág. 127)

La lógica binaria de la pena se extiende a todos los espacios que cubre el discurso mismo, los actos son correctos o incorrectos o las personas son inocentes o culpables. Por lo tanto, a partir de esta caracterización, el derecho penal es un tipo de derecho que conlleva a un cuadro simplista del hombre y sus actos. El conjunto de hipótesis construidas en forma de sistema que encierra los argumentos que soportan y limitan a que un acto sea correcto o incorrecto se le conocerá como teoría del delito, en la que consecuentemente se expondrán las situaciones en las cuales una persona recibirá un castigo así como las situaciones en que estaría eximido del mismo (causales de

\footnotetext{
${ }^{3}$ Para una introducción a los diferentes movimientos o escuelas que soportan el derecho penal occidental, la obra emblemática en la literatura penal colombiana es la del profesor Nodier Agudelo Betancur, quien en diferentes textos se ha preocupado por esclarecer las semejanzas y diferencias de las escuelas y esquemas del derecho penal (Agudelo, 2007).

${ }^{4}$ Esta imagen generada por el derecho penal moderno muestra su carácter absoluto en el sentido más puro, mostrando que hasta los discursos más nobles, impregnados de garantías y teorías novedosas que apuntan a la utópica humanización del derecho penal, queda reducido al carácter totalizante y totalitario de este discurso. En ese sentido, no hay diferencia alguna entre las teorías normativistas que reducen las garantías materiales y procesales, con aquellas que pretenden volver al iluminismo legalista del siglo XIX, porque el discurso jurídico penal es un discurso del absoluto, es un discurso que se limita al todo o nada.
} 
ausencia de responsabilidad). Es así como la teoría del delito es por antonomasia el discurso de los simplismos, el discurso que reduce sus actos a la lógica del "todo o nada".

Este discurso de los simplismos tiende a generar otras consecuencias que hace más cómodas la aplicación del castigo. En primer lugar, el derecho tiende a fijarse más en los actos que en las interacciones (Christie, 1989, pág. 132). El universo discursivo del castigo se acciona a partir de un momento, un acto. El código penal describe conductas negativas para la sociedad en tanto protección de un bien jurídico tutelado (Roxin, 2002), que en sí mismo genera un mandato de cómo debe comportarse el sujeto en sociedad, matar una vida está mal, salvará una vida está bien (Christie, 1989, pág. 128). Así mismo, este interés por penalizar el acto en el proceso de judicialización de la víctima del sistema penal (el delincuente) obliga a un proceso de adecuación que no tiene en cuenta las interacciones de los sujetos, "cuanto menos sepamos de una situación en las que se relaciona el delito, más simple y fácil será la tarea de clasificarlo".(Christie, 1989, pág. 128) Por otro lado, el derecho penal tiende a fijarse más en los sistemas biológicos de la personalidad que en los sistemas sociales. "cuando se trata de personas, las características dicotómicas simplificadas parecen al menos mucho más útiles, "psicópata", "monstruo", "criminal”, "hombre peligroso", son los términos que utilizan una y otra vez la descripción general de aquellos que han estado en contacto con la maquinaria del derecho penal". (Christie, 1989, pág. 128)

El sistema judicial hace uso excesivo del saber médico a la hora de individualizar al delincuente ${ }^{5}$, generando categorías más cómodas, convirtiendo al derecho penal como el instrumento que excluye infinitamente al sujeto de los sistemas sociales.

Es así como la actividad científica de quien pretende inventar un sistema teórico o un esquema que le de racionalidad al delito, haciendo caso omiso a que el dolor es su principal instrumento, se perfila a la minimización de atributos que tienen singular relevancia a la hora de castigar.

\section{CONSIDERACIONES FINALES}

Comprender la construcción y los efectos de la teoría penal en un contexto determinado no puede apartarse de las implicaciones políticas que estas suponen, pues sin duda alguna, las formas en cómo se elaborara o aplica, limitará o sistematizará garantías que abren el paso a lo permitido en sociedad. Por otro lado, si bien el campo académico comprende que la teoría penal es asumida como un pensamiento sistemático, pues obedece a un sistema de concatenación ascendiente con pretensiones de racionalización de un fenómeno, Es ineludible la separación que carga el conjunto de criterios que llamamos comúnmente teoría del delito en tanto que toda política es una tecnopolítica.

\footnotetext{
${ }^{5}$ La idea de individualizar al imputado en las diferentes audiencias del proceso penal es más que un acto de regresión a una etapa ya superada. El positivismo criminológico se muestra en la historia del pensamiento penal como el más sincero de los discursos, fundamentando al derecho penal en su línea más radical, como el exterminio de las bacterias que dañan el cuerpo social (Garofalo, 1912) (Zaffaroni, 2005). Doscientos años después sigue la misma tendencia anacrónica en el discurso penal, un discurso racista, que con la ayuda de la medicina pretende ejercer control sobre los extraños. El saber médico facilita la individualización del sujeto y con ello, la reafirmación de la lógica binaria y excluyente de determinado sujeto. La práctica dicotómica del discurso jurídico penal, reafirma el peligrosismo xenofóbico del siglo XIX, extendiéndose a manera de falange por las diferentes agencias que controlan el tejido social.
} 
Cuando se pretende eliminar el método jurídico para caer en el puro discurso político, el producto sea un discurso clientelista de oportunidad sin contenido racional (o con racionalidad propia, que es la del Estado de policía, o sea la funcionalidad para quien manda). No importa si la naturaleza del discurso jurídico penal se ha tenido en cuenta en elaborarlo, porque siempre será lo que es, aunque quien lo elabore lo ignore. Pueden elaborarse conceptos y aun enteros sistemas jurídico-penales ignorando su esencia policía y sus consecuencias reales: esto dependerá de la mayor o menor enajenación o alienación política del teórico.(Zaffaroni, 2005, pág. 75)

La desactivación del discurso jurídico penal a partir de su análisis político no se refiere al punto de origen con el que se ha construido. La pretensión de buscar la intencionalidad del discurso mostraría una distorsionada proyección lineal de la política, como si todos sus actores elaboraran discursos en los que trataran hasta sus últimas consecuencias y sus más mínimos detalles. Así mismo, un análisis que pretenda buscar el punto de origen de un autor, buscar el sentido ideológico de tal postura no deja de ser peligroso porque semejantes análisis de una u otra forma terminan motivadas razones afectivas. (Zaffaroni, 2005, pág. 75)

Un abordaje con estas pretensiones implica exponer la exterioridad de la teoría penal, "no del discurso hacia el interior, sino a partir del discurso mismo, de su aparición y de su regularidad, ir hacia sus condiciones externas de posibilidad, hacia lo que da motivo a la serie aleatoria de esos acontecimientos que fija los límites" (Foucault, 2002). Solo a partir de la exterioridad es que podremos notar los puntos de fuga con los cuales se contradice el discurso jurídico, la construcción de subjetividades, y con ello, los excesos de poder selectivo que carga consigo el poder punitivo.

\section{REFERENCIAS BIBLIOGRÁFICAS}

AGUDELO, N. (2007) “Curso de Derecho Penal”. Esquemas del Delito. Bogotá: Temis.

BAUMAN, Z. (2004) “La Sociedad Sitiada”. México: Fondo de Cultura Económica.

BECCARIA, C. (2010) “De los delitos y de las penas”. Bogotá: Temis.

BUSTOS, J., \& BERGALLI, R. (1983) “El Pensamiento criminológico”. Vol. I. Un análisis Crítico. Bogotá: Temis.

CARRARA, F. (2004) “Programa de derecho criminal”. (Tomo 1, volumen I: parte general). Bogotá: Temis.

CARRILLO, Y. (2009) "Derecho, Discurso y Poder". Tres ensayos sobre la relación del derecho y el poder político. Cartagena: Universidad Libre.

CHRISTIE, N. (1989) “Las imágenes del hombre en el Derecho Penal Moderno”. En: Cohen, Hulsman, Christie y otros. Abolicionismo penal. Buenos Aires: Ediar.

FERRI, E. (2004) “Sociología Criminal”. Tomo I. Madrid: Centro Editorial de Góngora.

FOUCAULT, M. (1996) “La verdad y las formas jurídicas”. Barcelona: Gedisa. 
FOUCAULT, M. (2002) “El orden del discurso”. Barcelona: Fabula Tusquets Editores.

GAROFALO, R. (1912) "La Criminología". Estudio sobre la naturaleza del crimen y teoría de la penalidad. Madrid: Daniel Jorro.

KRAEMER, H., \& SPRENGER, J. (1986) “El Malleus Malleficaurum”. El Martillo de las Brujas. Madrid: Ediciones Orión.

MORÓN, M. (2009) “Aproximación del contexto histórico de las ideas de la escuela positivista italiana”. En: Memorias del VIII Congreso de Filosofía del Derecho y Filosofía Social. Manizales: Universidad de Manizales.

MUÑOZ-CONDE, F. (1985) “Derecho Penal y Control Social”. Jerez: Fundación Universitaria de Jerez.

PAVARINI, M. (2003) "Control y Dominación". Teorías criminológicas burguesas y proyecto hegemónico. México DF: Siglo XXI editores.

ROXIN, C. (2002) "Problemas fundamentales de política criminal y derecho penal”. México Df: Universidad Nacional Autónoma de México.

ZAFFARONI, E. R. (2002) “Derecho Penal”. Parte General. Buenos Aires: Ediar.

ZAFFARONI, E. R. (2005) “En torno de la cuestión penal”. Montevideo-Buenos Aires: Editorial B de F.

ZAFFARONI, E. R. (2005) “Legitimación del control penal de los extraños". En Y. Reyes Alvarado, Dogmática y criminología. Dos visiones complementarias del fenómeno delictivo. Homenaje de los grandes tratadistas a Alfonso Reyes Echandia (págs. 618-631). Bogotá: Leyer.

ZAFFARONI, E. R. (2006) “El enemigo en el Derecho Penal”. Bogotá: Grupo Editorial Ibáñez - Universidad Santo Tomas. 